\title{
The role of stress-activated protein kinase signaling in renal pathophysiology
}

\author{
F.Y. Ma, J. Liu and D.J. Nikolic-Paterson \\ Department of Nephrology and Monash University Department of Medicine, Monash Medical Center, \\ Clayton, Victoria, Australia
}

Correspondence to: D.J. Nikolic-Paterson, Department of Nephrology, Monash Medical Center, 246 Clayton Road, Clayton, Victoria 3168, Australia

Fax+61-3-9594-6530. E-mail: david.nikolic-paterson@med.monash.edu.au

\begin{abstract}
Two major stress-activated protein kinases are the p38 mitogen-activated protein kinase (MAPK) and the c-Jun amino terminal kinase (JNK). p38 and JNK are widely expressed in different cell types in various tissues and can be activated by a diverse range of stimuli. Signaling through p38 and JNK is critical for embryonic development. In adult kidney, p38 and JNK signaling is evident in a restricted pattern suggesting a normal physiological role. Marked activation of both p38 and JNK pathways occurs in human renal disease, including glomerulonephritis, diabetic nephropathy and acute renal failure. Administration of small molecule inhibitors of p38 and JNK has been shown to provide protection from renal injury in different types of experimental kidney disease through inhibition of renal inflammation, fibrosis, and apoptosis. In particular, a role for JNK signaling has been identified in macrophage activation resulting in up-regulation of pro-inflammatory mediators and the induction of renal injury. The ability to provide renal protection by blocking either p38 or JNK indicates a lack of redundancy for these two signaling pathways despite their activation by common stimuli. Therefore, the stress-activated protein kinases, p38 and JNK, are promising candidates for therapeutic intervention in human renal diseases.
\end{abstract}

Key words: p38; c-Jun amino terminal kinase; Inflammation; Fibrosis; Apoptosis; Renal pathophysiology

Presented at the IV Miguel R. Covian Symposium, Ribeirão Preto, SP, Brazil, May 23-25, 2008.

F.Y. Ma and D.J. Nikolic-Paterson are funded by the Australian National Health and Medical Research Council.

Received June 4, 2008. Accepted September 18, 2008

\section{Introduction}

The stress-activated protein kinases (SAPK) are a group of serine/threonine kinases belonging to the mitogen-activated protein kinase (MAPK) family. The two major SAPK are C-Jun amino terminal kinase (JNK) and p38 MAPK, which play an essential role in mediating the cellular response to various stresses by modulating transcription factor function and thereby changing the pattern of gene transcription. This operates by direct phosphorylation of transcription factors, or by an indirect mechanism involving the phosphorylation of MAPK-activated protein kinases (MAPKAPK). A diverse range of biological functions can be induced through activation of the p38 and JNK pathways, including differentiation, proliferation, inflammation, apoptosis, and fibrosis (1). p38 and JNK are activated in response to a wide range of stimuli such as pro-inflammatory cytokines, Toll-like receptor activation in the innate immune response, a variety of growth factors, and stresses such as reactive oxygen species, osmotic stress, hyperglycemia and UV irradiation (1) (see Figure 1). Ligand-based activation of cell surface receptors is linked to activation of a three-tiered MAPK cascade via the p21-activated kinase family of enzymes that bind to and are activated by small GTPases of the Cdc42 and Rac families. Phosphorylation of the activation loop in the JNK and p38 kinases operates via a cascade of a MAP kinase kinase kinase (MAP3K), a MAP kinase kinase (MAP2K), and then a MAPK (see Figure 1). There is a considerable redundancy in the different MAP3Ks that can lead to activation of p38 and JNK, whereas direct activation of $\mathrm{p} 38$ and JNK by MAP2K is restricted to MAPK 
kinase (MKK) 3 and 6 or MKK4 and 7, respectively (see Figure 1). Scaffolding proteins, such as the family of JNK interacting proteins (JIP1-4), facilitate the three-tiered phosphorylation cascade by binding these kinases in close proximity. These scaffolding proteins may also be important in determining the specificity of SAPK signal transduction (2).

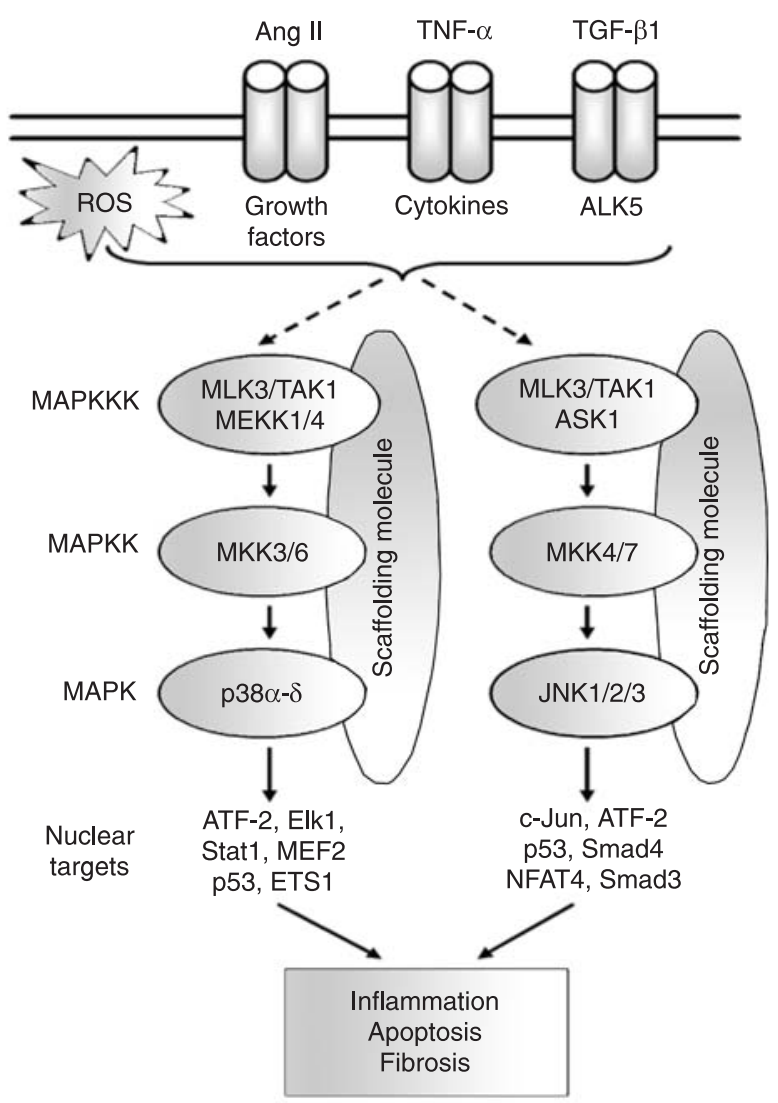

Figure 1. Overview of the stress-activated protein kinase (SAPK) signaling pathways, which is a subset of the mitogen-activated protein kinase (MAPK) family. Activation of different receptor types, such as G-protein coupled receptors for angiotensin II (ANG II) and the receptor tyrosine kinases for tumor necrosis factor alpha (TNF- $\alpha$ ) or transforming growth factor-beta 1 (TGF$\beta 1$ ), leads to the activation of MAP kinase kinase kinases (MAPKKK). These kinases can also be activated by reactive oxygen species (ROS), osmotic stress and UV irradiation through poorly defined intracellular mechanisms. The MAPKKK-MAPKKMAPK phosphorylation cascade is facilitated by scaffold proteins, which bind members of the MAPKKK, MAPKK and MAPK families in close proximity. There is a variety of different MAPKKK, whereas there are only two MAPKK, which are usually involved in phosphorylating the terminal JNK or p38 kinases. The stress-activated protein kinases can then translocate to the nucleus and modulate the function of a variety of transcription factors through phosphorylation, which induces a change in the pattern of gene transcription resulting in a biological response.
Inactivation of SAPK signaling is achieved by removal of phosphate groups from the activation loop in the JNK and p38 kinases. This is performed by members of a structurally distinct subfamily of dual-specificity (Thr/Tyr) protein phosphatases in a process regulated in two ways. First, the specificity of action by MAPK phosphatases (MKP) is achieved by interaction with their substrate kinases through a modular kinase interaction motif (KIM) located within the N-terminal non-catalytic domain of the protein. In addition, MAPK binding is often accompanied by enzymatic activation of the $\mathrm{C}$ terminal catalytic domain of the MKP, thus ensuring specificity of phosphatase action. Second, MKP levels are tightly controlled at the transcriptional level, providing a rapid negative feedback in response to SAPK signaling (3).

Further selectivity and regulation of SAPK signaling comes from the presence of several isoforms of both p38 and JNK in mammalian cells. The p38 SAPK has four distinct isoforms ( $p 38 \alpha, \beta, \gamma$ and $\delta$ ), which are encoded by individual genes. Of these isoforms, p38 $\alpha$ and p38 $\beta$ are ubiquitously expressed in most tissues; whereas p38 $\gamma$ and p38 $\delta$ have more restricted expression pattern (4). Genetic deletion of $p 38 \alpha$ induces embryonic death of mice due to placental defects. In contrast, mice with p38 $\beta, \gamma$, or $\delta$ knockout show a normal phenotype (5). Most of our understanding of p38 kinase function comes from the use of pharmacological inhibitors of the p38 $\alpha$ and p38 $\beta$ isoforms. Thus, it is difficult to discriminate between the function of $p 38 \alpha$ and p38 $\beta$, although reciprocal effects of p38 $\alpha$ and p38 $\beta$ on iNOS expression in mesangial cells have been described (6). In contrast, the role of p38 $\gamma$ and p38 in health and disease is poorly understood.

There are also multiple isoforms of JNK (JNK1, 2, and 3), which are encoded by individual genes and alternative mRNA splicing can give rise to even greater enzyme heterogeneity (7). While the expression of JNK3 is largely confined to the central nervous system, both JNK1 and JNK2 are widely expressed in many cell types in most tissues. Genetic deletion of a single JNK gene has little impact upon mouse development and survival. However, combined deletion of JNK1 and JNK2 is fetal lethal (5), indicating considerable redundancy between these kinases.

\section{SAPK in renal physiology}

p38 MAPK and JNK signaling is evident during kidney development in the rat (8). This appears to be important in kidney development since the addition of a p38 inhibitor to cultured metanephroi impaired cell proliferation and nephrogenesis (9). In the adult rodent and human kidney, there is limited p38 MAPK activation as assessed by 
immunostaining and Western blotting for phosphorylatedp38 (p-p38) $(10,11)$. p38 activation is evident in a small number of podocytes, parietal epithelial cells, cells of the macula densa and some tubular epithelial cells $(10,11)$. This limited activation of p38 in tubular cells may be related to osmotic stress, as in vitro studies have shown that hypertonic stress activates p38 MAPK signaling in tubular epithelial cells (12), and this activation may be linked to reorganization of the actin cytoskeleton in response to hypertonic cell shrinkage (13). An interesting recent finding is that administration of the p38 MAPK inhibitor, SB202190, induced a reduction in mean arterial blood pressure, glomerular filtration rate, and filtration fraction in both normal and diabetic rats (14). Whether this operates by modulating p38 function in cells of the macula densa, or whether p38 regulates endothelium-dependent vasodilation has yet to be established $(11,14)$. One other piece of data suggesting a role for $\mathrm{p} 38$ signaling in renal physiology comes from the finding that mice heterozygote for the $\mathrm{p} 38 \alpha$ gene $(p 38 \alpha+/-)$ appear normal but with age exhibit increased water intake and a higher kidney weight. These kidneys develop dilation of proximal convoluted tubules, vacuolar degeneration, focal interstitial fibrosis/inflammation, and enlargement of Bowman's capsule with advancing age (15).

Signaling via the JNK pathway is restricted to cells of the collecting duct and occasional parietal epithelial cells in normal kidney (16). Examination of gene-deficient mice has shown that JNK signaling in normal kidney can operate via JNK1 or JNK2 (16). This low level JNK activation may also represent a response to osmotic stress since JNK activation can be induced in rat renal epithelial cells by hypotonic stimuli (17). In addition, sodium reabsorption from tubules may also be affected by JNK activation through regulation of the synthesis of $\mathrm{Na-K}$-ATPase $\gamma$-subunit $(17,18)$. Administration of JNK inhibitor drugs to rats has shown no overall or renal toxicity $(16,19)$, suggesting that JNK signaling is not critical for renal physiology - although this needs to be rigorously examined.

\section{SAPK in human kidney disease}

Immunostaining of human biopsy specimens identified a marked increase in the number of p-p38+ cells in glomeruli and tubules in non-proliferative and proliferative forms of glomerulonephritis and a substantial increase in interstitial p-p38+ cells in proliferative glomerulonephritis (10). p38 activation was identified in intrinsic renal cells (podocytes, endothelial and tubular cells), infiltrating macrophage and neutrophils, and in alpha smooth muscle actin positive ( $\alpha$-SMA+) myofibroblasts. The number of $p$ - p38+ glomerular cells correlated with segmental proliferative and necrotic lesions, crescent formation, and macrophage accumulation. Meanwhile, interstitial p38 activation correlated with the degree of interstitial inflammation. There was also a correlation between renal failure and the number of p-p38+ glomerular, tubular, and interstitial cells; while proteinuria correlated with the number of p-p38+ podocytes, tubular, and interstitial cells $(10,20)$. A significant increase in p38 activation is also evident in human and experimental diabetic nephropathy $(20,21)$, with the number of p-p38+ tubulointerstitial cells reflecting the severity of tubulointerstitial lesions (22). These studies suggest that p38 activation may play an important pathogenic role in human renal diseases.

Activation of JNK signaling has also been examined in human kidney disease. Immunostaining for phosphorylated-c-Jun, a well-defined marker of JNK signaling, identified a striking increase in JNK activation in kidney diseases including various glomerulonephritis, hypertension and diabetic nephropathy (23). p-c-Jun staining was evident in many glomerular and tubular cells. Indeed, the number of $\mathrm{p}$-c-Jun+ glomerular cells correlated with the degree of glomerulosclerosis, while tubulointerstitial p-cJun staining correlated with interstitial fibrosis and renal dysfunction, implicating JNK signaling in the pathogenesis of different forms of human kidney disease (23).

\section{SAPK in experimental kidney disease}

The functional role of p38 and JNK signaling in a variety of animal models of kidney disease has been examined by administration of small molecular weight kinase inhibitors, the results of which are listed in Table 1. An important consideration is that p38 and JNK are activated in both intrinsic renal cell types as well as in inflammatory cells. Thus, it remains difficult to identify, in most situations, which cell types are the main target in the beneficial effects of these kinase inhibitor drugs.

\section{p38 MAPK in glomerular disease}

Anti-glomerular basement membrane (GBM) glomerulonephritis is an aggressive inflammatory disease in which renal injury is macrophage dependent (24). Rat models of anti-GBM disease exhibit a dramatic increase in p38 activation in glomeruli, which is followed by up-regulation of p38 in the tubulointerstitium, being evident in infiltrating macrophages, neutrophils, glomerular endothelial cells, podocytes, tubular epithelial cells, and myofibroblasts $(25,26)$. Blocking p38 $\alpha / \beta$ signaling in several independent studies using different kinase inhibitors successfully suppressed proteinuria and histological damage in this model (25-27). Specific 
effects of p38 blockade included inhibition of endothelial Pselectin expression resulting in a diminished neutrophil infiltrate (25), and the suppression of up-regulation of monocyte chemoattractant protein-1 (MCP-1), which was associated with inhibition of renal macrophage infiltration and suppression of glomerular damage $(26,27)$. Furthermore, delayed treatment with a p38 inhibitor was able to suppress estab- lished anti-GBM disease (27).

In MRL-Fas ${ }^{\text {Ipr }}$ mice, a model of lupus nephritis, treatment with the p38 inhibitor FR167653 suppressed renal pathology and prolonged survival (28). These protective effects were associated with reduced renal macrophage and T cell infiltration, MCP-1 and TNF- $\alpha$ expression, and glomerular lgG deposition (28).

Table 1. A summary of p38 and c-Jun amino terminal kinase (JNK) blockade studies in experimental kidney disease.

\begin{tabular}{|c|c|c|c|}
\hline Disease model & Inhibitor & Outcome & Reference \\
\hline \multicolumn{4}{|l|}{ p38 inhibitor studies } \\
\hline \multirow[t]{3}{*}{ Anti-glomerular basement membrane glomerulonephritis } & NPC 31145 & $\begin{array}{l}\downarrow \text { proteinuria } \\
\downarrow \text { inflammation }\end{array}$ & 25 \\
\hline & FR167653 & $\begin{array}{l}\downarrow \text { proteinuria } \\
\downarrow \text { inflammation }\end{array}$ & 26 \\
\hline & $\mathrm{RO} 4399247$ & $\begin{array}{l}\downarrow \text { proteinuria } \\
\downarrow \text { inflammation }\end{array}$ & 27 \\
\hline Lupus nephritis & FR167653 & $\begin{array}{l}\uparrow \text { survival } \\
\downarrow \text { autoantibody } \\
\downarrow \text { proteinuria } \\
\downarrow \text { inflammation }\end{array}$ & 28 \\
\hline Puromycin aminonucleoside nephrosis & FR167653 & $\begin{array}{l}\downarrow \text { proteinuria } \\
\downarrow \text { podocyte injury }\end{array}$ & 29 \\
\hline \multirow[t]{2}{*}{ Adriamycin nephropathy } & FR167653 & $\begin{array}{l}\downarrow \text { proteinuria } \\
\downarrow \text { inflammation }\end{array}$ & 29 \\
\hline & SB203580 & $\begin{array}{l}\downarrow \text { proteinuria } \\
\downarrow \text { inflammation }\end{array}$ & 30 \\
\hline \multirow[t]{2}{*}{ Spontaneously hypertensive-stroke-prone rat model } & FR167653 & $\begin{array}{l}\downarrow \text { proteinuria } \\
\downarrow \text { inflammation }\end{array}$ & 58 \\
\hline & SB239063 & $\begin{array}{l}\downarrow \text { glomerulosclerosis } \\
\uparrow \text { survival } \\
\downarrow \text { proteinuria }\end{array}$ & 59 \\
\hline High-renin Ren-2 rats & SB239063 & $\downarrow$ renal damage & 60 \\
\hline Heymann's nephritis & FR167653 & $\uparrow$ proteinuria & 33 \\
\hline Subtotal nephrectomy & NPC 31169 & $\begin{array}{l}\uparrow \text { proteinuria } \\
\downarrow \text { renal function } \\
\uparrow \text { inflammation }\end{array}$ & 34 \\
\hline Obstructed kidney & NPC 31169 & $\downarrow$ fibrosis & 42 \\
\hline Renal ischemia-reperfusion injury & FR167653 & $\begin{array}{l}\uparrow \text { renal function } \\
\downarrow \text { tubular damage } \\
\downarrow \text { inflammation }\end{array}$ & 48 \\
\hline \multicolumn{4}{|l|}{ JNK inhibitor studies } \\
\hline Rat anti-glomerular basement membrane glomerulonephritis & CC-401 & $\begin{array}{l}\downarrow \text { proteinuria } \\
\downarrow \text { inflammation }\end{array}$ & 16 \\
\hline Obstructed kidney & CC-401 & $\downarrow$ fibrosis & 19 \\
\hline Renal ischemia-reperfusion injury & SP600125 & $\begin{array}{l}\uparrow \text { renal function } \\
\downarrow \text { tubular damage } \\
\downarrow \text { inflammation }\end{array}$ & 47 \\
\hline Cisplatin-induced acute renal failure & SP600125 & $\begin{array}{l}\uparrow \text { renal function } \\
\downarrow \text { tubular damage } \\
\downarrow \text { inflammation }\end{array}$ & 50 \\
\hline
\end{tabular}


Blockade of $\mathrm{p} 38$ signaling has also been directly implicated in preventing podocyte damage and associated proteinuria. Consistent with human studies (10), p38 activation in podocytes was evident just prior to the onset of proteinuria in models of puromycin aminonucleoside (PAN) nephrosis and adriamycin nephropathy (29). Pre-treatment with a p38 inhibitor prevented podocyte damage and suppressed proteinuria in both models $(29,30)$, arguing that p38 signaling is involved in podocyte injury leading to proteinuria. This postulate is supported by a number of studies. Albumin overload in vivo and in vitro induced podocyte injury and proteinuria via a transforming growth factor-beta 1 (TGF- $\beta 1$ )/p38 pathway (31), while p38 signaling was shown to be required for PAN-induced actin reorganization in cultured podocytes (29). In addition, p38 signaling is required for TGF- $\beta 1$ - and angiotensin II-mediated podocyte apoptosis (32). However, a quite different result was found in passive Heymann's nephritis, a rat model of complement-dependent podocyte damage. Blockade of p38 signaling was found to exacerbate podocyte damage and proteinuria in vivo, while antibody and complement mediated damage of cultured podocytes was also shown to be dependent upon p38 activation. In addition, increased p38 activation induced by over-expression of a constitutively active mutant of TGF- $\beta 1$-activated kinase 1 (TAK1), a kinase upstream of $p 38$, was shown to suppress antibody and complement mediated podocyte damage (33).

Another setting in which p38 blockade was found to be detrimental was in $5 / 6$ subtotal nephrectomy in rats, in which administration of a p38 inhibitor accelerated renal disease (34). This exacerbation of disease was attributed to an up-regulation of extracellular signal-regulated kinase (ERK) signaling.

\section{JNK in glomerular disease}

There is also a marked increased in JNK activity in rat anti-GBM glomerulonephritis, with immunostaining for $p$ JNK and p-C-Jun showing JNK activation in glomerular macrophages, podocytes, tubular epithelial cells and $\alpha$ SMA+ myofibroblasts (16). The role of JNK in macrophage-mediated renal injury in this model was addressed using an adoptive transfer approach. Administration of a JNK inhibitor to cultured macrophages before their transfer into leukocyte-depleted rats given anti-GBM serum did not prevent macrophage recruitment into glomeruli, but it profoundly inhibited the induction of proteinuria and mesangial cell proliferation indicating that the macrophage response had been modified (35). Indeed, JNK blockade markedly blunted the TNF- $\alpha$ response in cultured macrophages (35).
In subsequent studies, oral administration of a highly selected JNK inhibitor (CC-401) was used in a standard model of rat anti-GBM disease (16). CC-401 treatment was effective in suppressing JNK activity without modifying the increase in p38 and ERK activation. JNK blockade suppress proteinuria and reduced the severity of glomerular and tubulointerstitial lesions despite a marked glomerular macrophage infiltrate. Analysis showed that markers of macrophage activation (iNOS and TNF- $\alpha$ ) were suppressed by JNK blockade, whereas the T cell and humoral immune response were unaltered, leading to the conclusion that the beneficial effects of JNK blockade were due to inhibition of the macrophage pro-inflammatory response (16). These findings are supported by a recent study in which the genetic susceptibility of WKY rats to anti-GBM disease was attributed to up-regulation of JunD leading to increased AP-1 activity and a macrophage pro-inflammatory phenotype (36).

We examined JNK activation in a non-immune model of glomerular injury. A single bolus injection of PAN induces podocyte damage and apoptosis, which is associated with heavy proteinuria. We identified a striking induction of JNK signaling in glomerular podocytes on day 4 , the time at which proteinuria first becomes evident in this disease model (Figure 2), suggesting a potential role for JNK activation in podocyte damage. Functional studies are now required to determine whether JNK signaling directly promotes podocyte damage in disease models.

\section{SAPK in interstitial fibrosis}

All progressive forms of kidney disease involve a pathological process in which the accumulation of extracellular matrix replaces the cellular structure resulting in progressive fibrosis leading to end-stage renal failure. The role of growth factors, such as TGF- $\beta 1$ and angiotensin II, is well established in renal fibrosis. However, we are beginning to appreciate that SAPK signaling plays an important role in promoting fibrosis through stimulating fibroblast proliferation (37), fibroblast transition into $\alpha-S M A+$ myofibroblasts (38), TGF- $\beta 1$ production (19), TGF- $\beta 1$-induced collagen and fibronectin production (39), and in facilitating TGF- $\beta 1$ induced transition of tubular epithelial cells into myofibroblasts (40).

Unilateral ureter obstruction is a model widely used to study renal fibrosis. This model has a rapid onset of fibrosis in response to tubular mechanical stretch, which is independent of the immune response (41). There is a striking increase in p38 activation in both tubular epithelial cells and in interstitial $\alpha-S M A+$ myofibroblasts (42) in the obstructed kidney. Administration of a p38 $\alpha$ inhibitor was effective in reducing myofibroblast accumulation and col- 
lagen deposition in the obstructed kidney. Interestingly, p38 blockade did not prevent up-regulation of TGF- $\beta 1$ mRNA or protein, indicating that p38 signaling acts downstream of TGF- $\beta 1$ (42). In further studies, the contribution of the upstream kinase, MKK3, to p38 activation and renal fibrosis was examined in the obstructed kidney. Mkk3-/mice were found to have a compensatory up-regulation of MKK6 in the kidney, although p38 activation was still suppressed in both normal and obstructed kidney compared to wild-type mice (43). Mkk3-/- mice were not protected from developing renal fibrosis indicating redundancy between MKK3 and MKK6 in this response. However, Mkk3-/- mice were protected from tubular cell apoptosis, identifying a specific role for MKK3-p38 signaling in this response (43).
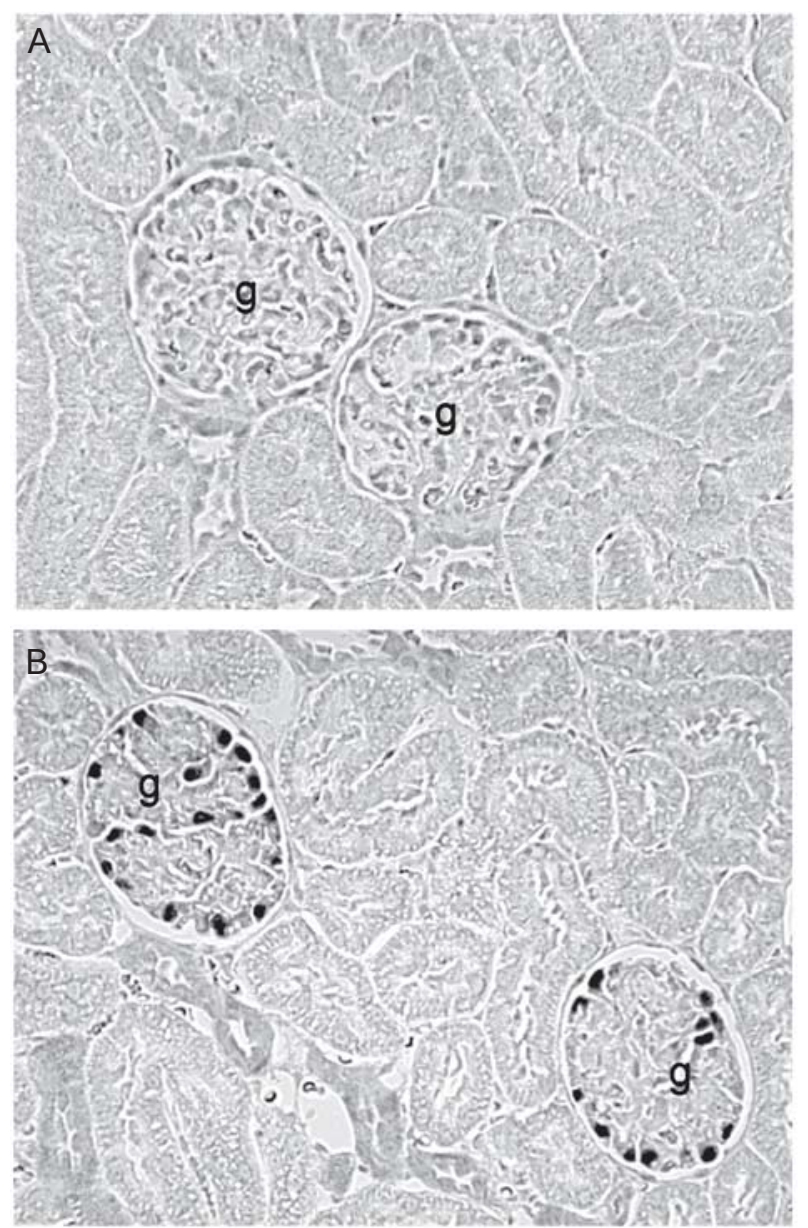

Figure 2. c-Jun amino terminal kinase (JNK) activation in rat puromycin aminonucleoside (PAN) nephrosis. JNK signaling was assessed by immunostaining at phospho-serine 63 in C-Jun. $A$, Normal rat kidney lacks phospho-c-Jun staining. $B$, Clear p-cJun staining is seen in glomerular podocytes on day 4 after PAN administration, the time when proteinuria is first evident prior to the peak of proteinuria on day $8 . \mathrm{g}=$ glomerulus.
The JNK signaling pathway also shows dramatic activation in tubular epithelial cells and myofibroblasts in the obstructed kidney (19). Administration of a JNK inhibitor was effective in preventing C-Jun phosphorylation and significantly reducing interstitial myofibroblast accumulation and collagen synthesis and deposition. In contrast to p38 blockade, inhibition of JNK signaling in the obstructed kidney caused a substantial reduction in TGF- $\beta 1 \mathrm{mRNA}$, indicating that JNK but not $\mathrm{p} 38$ signaling is required for upregulation of TGF- $\beta 1$ expression $(19,42)$. As both JNK1 and JNK2 isoforms are expressed in the kidney, interstitial fibrosis in Jnk1-/- and Jnk2-/- mice was examined in the obstructive kidney. Genetic deletion of either Jnk1 or Jnk2 did not prevent the marked activation of JNK signaling seen in the obstructed kidney, or affect the development of renal fibrosis, demonstrating redundancy between the two JNK isoforms. However, tubular epithelial cell apoptosis was significantly reduced in Jnk1-/- mice, identifying a specific role for this isoform in one aspect of renal injury (19). The identification of both MKK3 and JNK1 in tubular apoptosis in the obstructed kidney is supported by studies in which stretch-induced apoptosis of cultured tubular cells is dependent upon p38 and JNK signaling (44).

\section{SAPK in tubular damage}

There is a striking activation of the p38 and JNK pathways in acute renal failure induced by ischemia/reperfusion injury or administration of cisplatin. This is a rapid response that occurs primarily in tubular epithelial cells (45). The administration of p38 or JNK inhibitors has been shown to reduce acute renal failure, tubular apoptosis and histologic damage in models of renal ischemia/reperfusion (46-48). Similarly, blockade of p38 or JNK is protective against acute renal failure, tubular cell apoptosis and histologic damage in cisplatin-induced acute renal failure $(49,50)$. These findings are supported by in vitro studies in which blockade of p38 or JNK signaling can suppress tubular epithelial cell apoptosis induced by hypoxia or $\mathrm{H}_{2} \mathrm{O}_{2}$ (51). Furthermore, an antisense oligonucleotide approach has been used to demonstrate that JNK1 is required for hypoxia-induced apoptosis of human kidney cells (52), which is consistent with the protection of Jnk1-/mice from tubular cell apoptosis in the obstructed kidney (19).

In a different form of tubular damage, that of autosomal dominant polycystic kidney disease (PKD), immunohistochemistry staining identified phosphorylation of C-Jun and activating transcription factor 2 (ATF2) in tubular cysts in human and mouse PKD (53), suggesting that JNK/p38 MAPK signaling may be involved in cyst formation. In addition, the proteins PKD1 and PKD2 can both activate AP-1 via 
JNK (54). However, whether this has any relation to the increase in JNK signaling seen in PKD, in which PKD1 and/ or PKD2 are mutated, is not clear.

\section{Clinical potential for SAPK blockade}

The human and experimental studies described above make a strong argument for clinical trials of p38 and JNK inhibitors in human kidney disease. A number of p38 and JNK inhibitors have moved into clinical trials in non-renal fields. VX-702, an orally active p38 kinase inhibitor, has completed two phase II trials involving 130 patients with rheumatoid arthritis (55). Another p38 inhibitor, BIRB 796, has completed a multi-center trial in 284 patients with Crohn's disease (56). The PRECEPT trial tested the mixed lineage kinase inhibitor CEP-1347, which blocks JNK and p38 signaling, in patients with Parkinson's disease. The trial was stopped early (after 21 months) because of a lack of efficacy (57). However, all of these drugs have been well tolerated, apart from a mild and transient increase in serum transaminase levels in the BIRB 796 study (56). Thus, the safety profile of p38 and JNK inhibitors appears to be suitable for clinical trials in kidney disease, the question remains as to whether they will be efficacious.

\section{References}

1. Kyriakis JM, Avruch J. Mammalian mitogen-activated protein kinase signal transduction pathways activated by stress and inflammation. Physiol Rev 2001; 81: 807-869.

2. Morrison DK, Davis RJ. Regulation of MAP kinase signaling modules by scaffold proteins in mammals. Annu Rev Cell Dev Biol 2003; 19: 91-118.

3. Dickinson RJ, Keyse SM. Diverse physiological functions for dual-specificity MAP kinase phosphatases. J Cell Sci 2006; 119: 4607-4615.

4. Jiang $Y$, Gram H, Zhao M, New L, Gu J, Feng L, et al. Characterization of the structure and function of the fourth member of p38 group mitogen-activated protein kinases, p38delta. J Biol Chem 1997; 272: 30122-30128.

5. Gerits N, Kostenko S, Moens U. In vivo functions of mitogen-activated protein kinases: conclusions from knock-in and knock-out mice. Transgenic Res 2007; 16: 281-314.

6. Lui P, Zeng C, Acton S, Cok S, Sexton A, Morrison AR. Effects of p38MAPK isoforms on renal mesangial cell inducible nitric oxide synthase expression. Am J Physiol Cell Physiol 2004; 286: C145-C152.

7. Gupta S, Barrett T, Whitmarsh AJ, Cavanagh J, Sluss HK, Derijard B, et al. Selective interaction of JNK protein kinase isoforms with transcription factors. EMBO J 1996; 15: 27602770.

8. Omori S, Hida M, Ishikura K, Kuramochi S, Awazu M. Expression of mitogen-activated protein kinase family in rat renal development. Kidney Int 2000; 58: 27-37.

\section{Conclusions}

Human studies and functional blockade in experimental models have identified an important role for p38 and JNK signaling in a variety of renal diseases. Several important pathogenic mechanisms including renal inflammation, fibrosis and tubular damage can all be suppressed by targeting p38 or JNK signaling. Limited data suggest a role for SAPK in normal renal physiology, but this has not proven to be of concern in clinical trials using p38 or JNK inhibitors. Therefore, blockade of p38 and JNK signaling is a promising therapeutic strategy for the treatment of various forms of kidney disease.

\section{Acknowledgments}

We wish to acknowledge the work of many scientists that, due to space constraints, we were unable to cite. In addition, we acknowledge a potential conflict of interest since D.J. Nikolic-Paterson acts as a consultant for Celgene, which makes JNK inhibitor compounds, and Celgene has provided financial support to D.J. Nikolic-Paterson for studies of JNK inhibitors in kidney disease.

9. Hida M, Omori S, Awazu M. ERK and p38 MAP kinase are required for rat renal development. Kidney Int 2002; 61: 1252-1262.

10. Stambe C, Nikolic-Paterson DJ, Hill PA, Dowling J, Atkins RC. p38 Mitogen-activated protein kinase activation and cell localization in human glomerulonephritis: correlation with renal injury. J Am Soc Nephrol 2004; 15: 326-336.

11. Cheng HF, Wang JL, Zhang MZ, McKanna JA, Harris RC. Role of p38 in the regulation of renal cortical cyclooxygenase- 2 expression by extracellular chloride. J Clin Invest 2000; 106: 681-688

12. Padda R, Wamsley-Davis A, Gustin MC, Ross R, Yu C, Sheikh-Hamad D. MEKK3-mediated signaling to $p 38$ kinase and TonE in hypertonically stressed kidney cells. Am J Physiol Renal Physiol 2006; 291: F874-F881.

13. Bustamante M, Roger F, Bochaton-Piallat ML, Gabbiani G, Martin PY, Feraille E. Regulatory volume increase is associated with p38 kinase-dependent actin cytoskeleton remodeling in rat kidney MTAL. Am J Physiol Renal Physiol 2003; 285: F336-F347.

14. Komers R, Schutzer W, Xue H, Oyama TT, Lindsley JN, Anderson S. Effects of p38 mitogen-activated protein kinase inhibition on blood pressure, renal hemodynamics, and renal vascular reactivity in normal and diabetic rats. Transl Res 2007; 150: 343-349.

15. Maruyama M, Yagasaki Y, Sudo T, Osada H. Renal abnormalities in mice caused by insufficiency of p38alpha. $J$ 
Recept Signal Transduct Res 2003; 23: 173-183.

16. Flanc RS, Ma FY, Tesch GH, Han Y, Atkins RC, Bennett BL, et al. A pathogenic role for JNK signaling in experimental anti-GBM glomerulonephritis. Kidney Int 2007; 72: 698-708.

17. Taruno A, Niisato $\mathrm{N}$, Marunaka $\mathrm{Y}$. Hypotonicity stimulates renal epithelial sodium transport by activating JNK via receptor tyrosine kinases. Am J Physiol Renal Physiol 2007; 293: F128-F138.

18. Capasso JM, Rivard CJ, Berl T. Synthesis of the Na-KATPase gamma-subunit is regulated at both the transcriptional and translational levels in IMCD3 cells. Am J Physiol Renal Physiol 2005; 288: F76-F81.

19. Ma FY, Flanc RS, Tesch GH, Han Y, Atkins RC, Bennett BL, et al. A pathogenic role for c-Jun amino-terminal kinase signaling in renal fibrosis and tubular cell apoptosis. $J$ Am Soc Nephrol 2007; 18: 472-484.

20. Sakai N, Wada T, Furuichi K, Iwata Y, Yoshimoto K, Kitagawa $\mathrm{K}$, et al. p38 MAPK phosphorylation and NF-kappa B activation in human crescentic glomerulonephritis. Nephrol Dial Transplant 2002; 17: 998-1004.

21. Adhikary L, Chow F, Nikolic-Paterson DJ, Stambe C, Dowling J, Atkins RC, et al. Abnormal p38 mitogen-activated protein kinase signalling in human and experimental diabetic nephropathy. Diabetologia 2004; 47: 1210-1222.

22. Sakai N, Wada T, Furuichi K, Iwata $\mathrm{Y}$, Yoshimoto $\mathrm{K}$, Kitagawa $\mathrm{K}$, et al. Involvement of extracellular signal-regulated kinase and p38 in human diabetic nephropathy. Am J Kidney Dis 2005; 45: 54-65.

23. De Borst MH, Prakash J, Melenhorst WB, van den Heuvel MC, Kok RJ, Navis G, et al. Glomerular and tubular induction of the transcription factor c-Jun in human renal disease. J Pathol 2007; 213: 219-228.

24. Nikolic-Paterson DJ, Atkins RC. The role of macrophages in glomerulonephritis. Nephrol Dial Transplant 2001; 16 (Suppl 5): 3-7.

25. Stambe C, Atkins RC, Hill PA, Nikolic-Paterson DJ. Activation and cellular localization of the p38 and JNK MAPK pathways in rat crescentic glomerulonephritis. Kidney Int 2003; 64: 2121-2132.

26. Wada T, Furuichi K, Sakai N, Hisada Y, Kobayashi K, Mukaida N, et al. Involvement of p38 mitogen-activated protein kinase followed by chemokine expression in crescentic glomerulonephritis. Am J Kidney Dis 2001; 38: 11691177.

27. Sheryanna A, Bhangal G, McDaid J, Smith J, Manning A, Foxwell BM, et al. Inhibition of p38 mitogen-activated protein kinase is effective in the treatment of experimental crescentic glomerulonephritis and suppresses monocyte chemoattractant protein-1 but not IL-1beta or IL-6. J Am Soc Nephrol 2007; 18: 1167-1179.

28. Iwata $\mathrm{Y}$, Wada T, Furuichi K, Sakai N, Matsushima K, Yokoyama $\mathrm{H}$, et al. p38 Mitogen-activated protein kinase contributes to autoimmune renal injury in MRL-Fas Ipr mice. J Am Soc Nephrol 2003; 14: 57-67.

29. Koshikawa M, Mukoyama M, Mori K, Suganami T, Sawai K, Yoshioka $T$, et al. Role of p38 mitogen-activated protein kinase activation in podocyte injury and proteinuria in experimental nephrotic syndrome. J Am Soc Nephrol 2005; 16: $2690-2701$.

30. Li J, Campanale NV, Liang RJ, Deane JA, Bertram JF, Ricardo SD. Inhibition of p38 mitogen-activated protein ki- nase and transforming growth factor-beta1/Smad signaling pathways modulates the development of fibrosis in adriamycin-induced nephropathy. Am J Pathol 2006; 169: 15271540.

31. Yoshida S, Nagase M, Shibata S, Fujita T. Podocyte injury induced by albumin overload in vivo and in vitro: involvement of TGF-beta and p38 MAPK. Nephron Exp Nephrol 2008; 108: e57-e68.

32. Schiffer $M$, Bitzer $M$, Roberts IS, Kopp JB, ten Dijke $P$, Mundel $\mathrm{P}$, et al. Apoptosis in podocytes induced by TGFbeta and Smad7. J Clin Invest 2001; 108: 807-816.

33. Aoudjit L, Stanciu M, Li H, Lemay S, Takano T. p38 mitogen-activated protein kinase protects glomerular epithelial cells from complement-mediated cell injury. Am J Physiol Renal Physiol 2003; 285: F765-F774.

34. Ohashi R, Nakagawa T, Watanabe S, Kanellis J, Almirez RG, Schreiner GF, et al. Inhibition of p38 mitogen-activated protein kinase augments progression of remnant kidney model by activating the ERK pathway. Am J Pathol 2004; 164: 477-485.

35. Ikezumi Y, Hurst L, Atkins RC, Nikolic-Paterson DJ. Macrophage-mediated renal injury is dependent on signaling via the JNK pathway. J Am Soc Nephrol 2004; 15: 1775-1784.

36. Behmoaras J, Bhangal G, Smith J, McDonald K, Mutch B, Lai $P C$, et al. Jund is a determinant of macrophage activation and is associated with glomerulonephritis susceptibility. Nat Genet 2008; 40: 553-559.

37. Khalil N, Xu YD, O'Connor R, Duronio V. Proliferation of pulmonary interstitial fibroblasts is mediated by transforming growth factor-beta1-induced release of extracellular fibroblast growth factor-2 and phosphorylation of p38 MAPK and JNK. J Biol Chem 2005; 280: 43000-43009.

38. Hu Y, Peng J, Feng D, Chu L, Li X, Jin Z, et al. Role of extracellular signal-regulated kinase, p38 kinase, and activator protein-1 in transforming growth factor-beta1-induced alpha smooth muscle actin expression in human fetal lung fibroblasts in vitro. Lung 2006; 184: 33-42.

39. Tsukada S, Westwick JK, Ikejima K, Sato N, Rippe RA. SMAD and p38 MAPK signaling pathways independently regulate alpha1(I) collagen gene expression in unstimulated and transforming growth factor-beta-stimulated hepatic stellate cells. J Biol Chem 2005; 280: 10055-10064.

40. Rhyu DY, Yang Y, Ha H, Lee GT, Song JS, Uh ST, et al. Role of reactive oxygen species in TGF-beta1-induced mitogen-activated protein kinase activation and epithelial-mesenchymal transition in renal tubular epithelial cells. $J$ Am Soc Nephrol 2005; 16: 667-675.

41. Shappell SB, Gurpinar T, Lechago J, Suki WN, Truong LD. Chronic obstructive uropathy in severe combined immunodeficient (SCID) mice: lymphocyte infiltration is not required for progressive tubulointerstitial injury. J Am Soc Nephrol 1998; 9: 1008-1017.

42. Stambe C, Atkins RC, Tesch GH, Masaki T, Schreiner GF, Nikolic-Paterson DJ. The role of p38alpha mitogen-activated protein kinase activation in renal fibrosis. J Am Soc Nephrol 2004; 15: 370-379.

43. Ma FY, Tesch GH, Flavell RA, Davis RJ, Nikolic-Paterson DJ. MKK3-p38 signaling promotes apoptosis and the early inflammatory response in the obstructed mouse kidney. Am J Physiol Renal Physiol 2007; 293: F1556-F1563.

44. Nguyen HT, Hsieh MH, Gaborro A, Tinloy B, Phillips C, 
Adam RM. JNK/SAPK and p38 SAPK-2 mediate mechanical stretch-induced apoptosis via caspase-3 and -9 in NRK52E renal epithelial cells. Nephron Exp Nephrol 2006; 102: e49-e61.

45. Pombo CM, Bonventre JV, Avruch J, Woodgett JR, Kyriakis $\mathrm{JM}$, Force $\mathrm{T}$. The stress-activated protein kinases are major c-Jun amino-terminal kinases activated by ischemia and reperfusion. J Biol Chem 1994; 269: 26546-26551.

46. Li R, Ding T, Liu X, Li C. Influence of SB203580 on cell apoptosis and P38MAPK in renal ischemia/reperfusion injury. J Huazhong Univ Sci Technolog Med Sci 2006; 26: 5052.

47. Wang $Y$, Ji HX, Xing SH, Pei DS, Guan QH. SP600125, a selective JNK inhibitor, protects ischemic renal injury via suppressing the extrinsic pathways of apoptosis. Life Sci 2007; 80: 2067-2075.

48. Furuichi K, Wada T, Iwata Y, Sakai N, Yoshimoto K, Kobayashi KK, et al. Administration of FR167653, a new antiinflammatory compound, prevents renal ischaemia/reperfusion injury in mice. Nephrol Dial Transplant 2002; 17: 399407.

49. Ramesh G, Reeves WB. p38 MAP kinase inhibition ameliorates cisplatin nephrotoxicity in mice. Am J Physiol Renal Physiol 2005; 289: F166-F174.

50. Francescato HD, Costa RS, Junior FB, Coimbra TM. Effect of JNK inhibition on cisplatin-induced renal damage. Nephrol Dial Transplant 2007; 22: 2138-2148.

51. Wang L, Matsushita K, Araki I, Takeda M. Inhibition of C-Jun $\mathrm{N}$-terminal kinase ameliorates apoptosis induced by hydrogen peroxide in the kidney tubule epithelial cells (NRK-52E). Nephron 2002; 91: 142-147.

52. Garay M, Gaarde W, Monia BP, Nero P, Cioffi CL. Inhibition of hypoxia/reoxygenation-induced apoptosis by an antisense oligonucleotide targeted to JNK1 in human kidney cells. Biochem Pharmacol 2000; 59: 1033-1043.
53. Le $\mathrm{NH}$, van der Wal $\mathrm{A}$, van der Bent $\mathrm{P}$, Lantinga-van Leeuwen I, Breuning $\mathrm{MH}$, van Dam $\mathrm{H}$, et al. Increased activity of activator protein-1 transcription factor components ATF2, c-Jun, and c-Fos in human and mouse autosomal dominant polycystic kidney disease. J Am Soc Nephrol 2005; 16: 2724-2731.

54. Arnould T, Kim E, Tsiokas L, Jochimsen F, Gruning W, Chang JD, et al. The polycystic kidney disease 1 gene product mediates protein kinase $\mathrm{C}$ alpha-dependent and cJun N-terminal kinase-dependent activation of the transcription factor AP-1. J Biol Chem 1998; 273: 6013-6018.

55. Ding C. Drug evaluation: VX-702, a MAP kinase inhibitor for rheumatoid arthritis and acute coronary syndrome. Curr Opin Investig Drugs 2006; 7: 1020-1025.

56. Schreiber S, Feagan B, D'Haens G, Colombel JF, Geboes $\mathrm{K}$, Yurcov M, et al. Oral p38 mitogen-activated protein kinase inhibition with BIRB 796 for active Crohn's disease: a randomized, double-blind, placebo-controlled trial. Clin Gastroenterol Hepatol 2006; 4: 325-334.

57. Mixed lineage kinase inhibitor CEP-1347 fails to delay disability in early Parkinson disease. Neurology 2007; 69: 14801490.

58. Tojo A, Onozato ML, Kobayashi N, Goto A, Matsuoka H, Fujita T. Antioxidative effect of p38 mitogen-activated protein kinase inhibitor in the kidney of hypertensive rat. $J$ Hypertens 2005; 23: 165-174.

59. Behr TM, Nerurkar SS, Nelson AH, Coatney RW, Woods TN, Sulpizio A, et al. Hypertensive end-organ damage and premature mortality are p38 mitogen-activated protein kinase-dependent in a rat model of cardiac hypertrophy and dysfunction. Circulation 2001; 104: 1292-1298.

60. De Borst MH, Navis G, de Boer RA, Huitema S, Vis LM, van Gilst WH, et al. Specific MAP-kinase blockade protects against renal damage in homozygous TGR(mRen2)27 rats. Lab Invest 2003; 83: 1761-1770. 